\title{
The Paradox of the Regional Centres Unit: The Case of eThekwini Municipality
}

\author{
Bethuel Sibongiseni Ngcamu \\ Mangosuthu University of Technology, South Africa \\ ngcamub@mut.ac.za
}

\begin{abstract}
Municipalities have been operating without the unit or departmental strategic plans aligned to the Integrated Development Plans (IDPs). This has led to the fragmentation of their organograms or structures. The resultant to silo-ed organisational structures are characterised by inefficiency and ineptitude caused by cadre deployment, which has directly paralysed service delivery. The primary purpose of this study was to reveal the root causes of poor customer service and delivery in municipalities by interrogating the eThekwini Municipality's Regional Centres Unit operational activities. A qualitative case study research method was employed in this study. Data was collected through indepth interviews with a population size of 56 employees, as well as through focus groups constituted of 24 employees. A notable finding of this study was the unavailability of the approved unit's strategic plan which has resulted to the unaligned silo-ed structure, and unclear roles and responsibilities; and ineptitude of employees. The unaligned and silo-ed structures to the approved strategic plan within eThekwini Municipality's Regional Centres Unit have the potential value add to the literature in public administration on the ways to detect the hidden municipal administrative bottlenecks in improving the efficiency, effectiveness and acceleration of the municipal services to its customers.
\end{abstract}

Keywords: Regional Centres, strategy, IDP, customer service, competencies

\section{Introduction}

The municipal units or departments in South Africa have been operating without the approved strategic plans cascading from the approved Integrated Development Plan (IDP), which has exacerbated fragmented organograms or structures, silo mentality, incompetency and broken business processes. Fourie \& Jager (2005) argue that front line employees should be well informed about the organisation's mission, goals, strategies and organisational processes. This is evident at the eThekwini Municipality's Regional Centres Unit whereby the unity structures are perceived to follow emotions rather than strategic plans which have caused input and bureaucratic orientated business processes with reduced customer focus which has directly impacting negatively on customer care and service delivery. Different authors have cited outmoded municipal structures or organograms (Odendaal, 2003: 47); a lack of capacity to plan strategically (Mbele, 2010); strategy formulation without implementation (Miller \& Dess, 1996); and failure of the structure to follow strategy (Robbins, Odendaal \& Roodt, 2003) to have contributed to this fragmentation of structures; ambiguity and duplication of roles and responsibilities; silo mentality and incompetency in municipalities. With regard to silos working relationships, authors such as Engele (n.d.) and Brand \& Klein (2012: 23) have related such malpractices to municipal failures in executing the set and agreed objectives or standards. One of the research problems under-scrutiny and exposed in the literature thus far is whether municipal structures or organograms talks to the units or departmental strategic plans, which are aligned to the IDP. Furthermore, whether the intertwined strategic plan and the structure have a potential to influence the functioning of the customer care centres needs to be established. Kaplan \& Norton (2004) mention organisational structure capabilities as one of the leading measures of innovation.

Fortunately, this issue of competencies is gaining momentum and researchers are increasingly examining the competencies required by the municipality customer care units or departments (Marais \& Kroukamp, 2005) and SAMDI, 2003). However, Furguson \& Milliman (2001: 56) blame most of this phenomenon on the lack of commitment and skills of the frontline employees who are interacting with customers. The research objectives that are addressed by this study are to investigate whether a unit's strategic plan relate to the unit's structure or organogram and to investigate the underlying organisational causes of the malfunctioning of the Customer Care Centres located in the peri-urban or rural areas within eThekwini Municipality. This study will enlighten on the municipal decision-makers, as it will reveal the underlying and root causes of poor customer care and service delivery. It further advises municipal officials on the interventions that could be implemented to remedy this detrimental situation. The literature review that 
follows critiques strategic planning discourse, as well as silo mentality, competencies needed in customer care service and managerialism principles. The review is followed by a description of the research design, including the research approach; the nature of the respondents who participated in the study, and the manner in which the data was collected and analysed. The findings of the study are then presented and discussed, and recommendations made to the municipal decision-makers of the municipality. The article concludes by mentioning the limitations within the theoretical research and provides recommendations for future research.

\section{Literature Review}

The paradox of the strategic plans in local government: According to Ridder, Bruns \& Spier (2006: 87), key processes that support strategy are on integrated development planning system and processes; organisation structure(Van Rooyen, 2001: 62) and information systems and communication channels (Pryor, Anderson, Toombs \& Humphreys, 2007: 8). This suggests that municipal unit or departmental structures and fractured business processes that tend to be unresponsive to the needs of customers might hamper municipal officials in achieving the set and agreed objectives as per the approved strategic plan. This is supported by Odendaal (2003: 47) who claims that municipal structures, processes and technology are often outdated or obsolete and this could have a negative effect on sustainable development as well as on municipal service delivery. Furthermore, Kotler \& Andreasen (1996: 379-380) aver that effective service delivery is often sabotaged by the unresponsive actions of front-line employees who work directly with customers. It is widely documented that many South African municipalities lack the adequate capacity to plan strategically and translate strategic plans into budgets; to engage civil society effectively in the strategic planning (IDP) process; and to manage the implementation of strategic plans (Katoma \& Ungerer (2011: 33) and Mbele (2010: 54). Vatala (2005:1) defines an IDP as a road map that provides sign posts towards a particular direction. This direction is the vision of a municipality. An IDP is derived from section 56(2)(a-d) of the Local Government: Municipal Structures Act of 1998 (Act of 117) as amended by Act 58 of 1999, which mandates the Executive Mayor to identify the needs of the municipality, review and evaluate those needs in priority and makes recommendations to council, and further recommend or determine the best practice. In light of the above, it is quite evident that municipalities are failing to cascade the Integrated Development Plans (IDP) to units or departments; linking them to the operational plans; and linking them to individual employee's job descriptions, which could directly improve efficiency and effectiveness as well as speedy service delivery.

Haycock \& Labuschagne (2006: 257) noted that it is frequently indicated that the reason why strategic planning fails as a result, not of a poor plan, but rather of a lack of support from those who are crucial to its success (Firer, 2002: 21).Different authors have cited various root causes and fundamental problems for why strategic plans fails as emanating from the separation of thinking from action (Mintzberg, 1994: 275); knowledge without action and strategy formulation without implementation (Miller \& Dess, 1996: 379); and a separation of strategy from operations (Haycock \& Labuschagne (2006) and Robbins, Odendaal \& Roodt (2003: 320). Robbins et al. (2003) further contend that, since objectives are derived from the overall organisational strategy, it is only logical that strategy and structure should be closely linked and, more specifically, structure should follow strategy. Cascading the organisational strategic plan to units or departments and finally linking these to individual job descriptions could identify the deficiencies on the competencies required from the incumbent to achieve the agreed standards, while eliminating the silos. Fourie \& Jager (2005: 230) are of view that managers should be in a position to determine the existing scope of service delivery and standards in order to allow them to determine deficiencies and to prioritise services.

The politics of silos mentality in local government: Municipalities have historically been, and continue to be, highly silo-ed organisational structures with a poor record for integration, multi-faceted programmes, internal communication and coordination, and shared responsibility (Brand \& Klein, 2012: 23). Engele (n.d.) of in the opinion that, for companies that operate in silos, functional areas or distinctions do not communicate with others for numerous reasons. The result is confusion, paralysis, inefficient; decision-making and, ultimately, business failure. The author further argues that the root cause of silo behaviour is a lack of trust between functions or divisions. Such mistrust might be caused by divisions or slates emanating from the employee's political party (ANC), as their appointments are allegedly related to political cadre deployment. Mbele (2010: 52) avers that municipal officials cannot divorce party politics from administration. As a result, tensions flair, particularly when it comes to senior positions as it takes two months to appoint to these positions. However, due to interference the process 
can take up to six months. The author's findings indicate that one of the municipal manager indicated that political deployment is destroying municipalities. In his municipality, about $70 \%$ of appointments do not meet the requirements (grade) due to political deployment. It could be argued that incompetency, grade anomalies and unequal workload distributions in local government might be caused by employees who are favoured due to their political affiliations.

Ineptitude and customers service centres in local government: It is permissible that employees' reactive approach to excellent professional customer service might be the result of an absence of leadership style with clear and communicated strategies and plans to subordinates. Crous (2005:3) is of the opinion that a customer care service approach is designed to improve relationships and the handling of customers by realigning organisational strategies and processes towards satisfying customer' needs. The author further argues that genuine customer care is thus a by-product of internal relationships and cultures, which renders it a leadership issue that should be part of an overall organisational strategy. The White Paper on Transforming Public Service Delivery (Notice 1459 of 1997) requires municipalities to ensure that the customer care service approach is designed to improve relationships with as well as ways of handling customers. Fourie \& Jager (2005: 231) aver that the public service needs to be made more affordable, innovative and responsive to customer needs. The authors further state the public service that it needs to take more advantage and to utilise a range of partnerships so that the productive capacities in the private and non-profit sectors of society can be used to the maximum benefit of the public service's customers. It can be simplistically deduced that customer orientation and focus requires a combination of skills, knowledge, intellectual capabilities and partnerships.

Public officials lack the necessary skills to fulfil their mandate (Marais \& Kroukamp, 2005: 121). Rapea (2004: 33-34) \& SAMDI (2003: 9-63) argue that strategic capabilities and leadership; service delivery; innovation; people management and empowerment; client orientation; honesty and integrity; concern for others; impact and influence; and team leadership are the competencies required for leading a customer care. The latter authors failed to include decision-making and research skills as the most important competencies required for customer care employees to possess, in order to be able to gauge customer satisfaction by conducting both qualitative and quantitative research studies. Rapea (2004: 78) and Baily (1996: 37) suggest that leaders should receive the input needed to develop an external customersatisfaction mission which will meet a number of objectives, including defining the behaviour needed to support a customer focus. Strydom (2004: 15-272) simplistically points out that internal marketing is an organisation's effort to communicate with and motivate employees to share in the goal of improving customer satisfaction. The author alludes that this includes training employees and providing them with the necessary tools and skills to enhance service delivery to customers.

Managers in municipalities should exhibit particular skills and competencies in order to fulfil their developmental role and provide quality municipal services to inhabitants (Marais \& Kroukamp, 2005: 121). The authors allude to the case that individual managers may well possess the educational background required by their positions but the experience and the appropriateness of their positions may not be congruent with their requirements of their positions. The Municipal Systems Amendment Act of 2011 (Act 7 of 2011) bars municipal managers and managers directly accountable to municipal managers from holding political office in political parties. Section $54 \mathrm{~A}(3)$ (a) of the same Act states that if the person appointed does not have the prescribed skills, expertise, competencies or qualifications, (b) the appointment was otherwise made in contravention of the Act. The White Paper on the Transformation of the Public Service (1995) address the softer issues of service delivery improvement such as better people management; improvement of people skills; improved representation of employees and equity in service delivery; the changing of orientation; away from rule subservience towards an improved results focus; as well as improved management autonomy, efficiency and accountability. The recent amendments of the South African prescripts respond to the poor service delivery, which is mostly traced to the perceived appointments based on political affiliations, than meritocracy.

The managerialism of customer care centres: The South African public administration has been evolving over the past years from public administration to New Public Management (NPM) whereas legislation is still static and associated with outmoded applications of medieval governance. Siswana (2007:87) attests that evidence indicated that traditional public administration does not promote a results-based management (RBM) model, a model that ensures that a linkage between input-output outcomes that is crystal clear and implemented. This motivates for South African legislation to be transformed and aligned to the dynamics of New Public Management (NPM), which adopts the 
philosophy and principles of the private sector of managerialism. Mthembu (2001:2) contends that a shift from public administration to management is highly commendable due to the fact that South Africa, like other countries, is not immune to the impact of globalisation on the Public Service. The author further comments that the public management model is to be a strategy to meet the challenges of globalisation and to promote professionalism, accountability, transparency and service-oriented Public Service. Mafunisa (2003: 62) argues that professionalism is most effective when it begins at the top and proceeds downward throughout departmental structures. Despite the invention of the customer care centres in local government, these centres have seldom been mentioned in public administration literature (Caillier, 2009: 292). As a result, public organisations did not place a heavy emphasis on customer care service until local governments began using private sector concepts to reform the bureaucracy in the 1980s (Hendrick, 2000). It is evident that the municipal customer care centres in South Africa are lagging behind the principles and standards of managerialsm, which are output-oriented.

\section{Methodology}

Research approach: Due to the paucity of published data on how municipal IDPs are cascaded to units or department's strategic plans and how a structure is aligned to the latter, a inductive research approach was used in this study as the researcher commenced the research by collecting and exploring data without a predetermined theoretical or descriptive framework (Yin 2003).

Research strategy: A qualitative case study research method was used to gather data and provide perspective on the availability of the approved strategic plans aligned to the IDPs within eThekwini Municipality's Regional Centres Unit and the underlying organisational factors the led to the malfunctioning of the customer care centres located in the peri-urban or rural areas. Swanson \& Holton (1997) state that a qualitative design is appropriate for this study because it is used when a researcher wants to study a phenomenon in its natural setting and interpret it in terms of the meanings attached in that situation. Patton (2001) supports the notion of the researcher's involvement and immersion into the research by stating that the real world is subject to change and, therefore, a qualitative researcher should be present during the changes to record an event before and after the change occurs. Qualitative studies focus on the social processes and the meanings attached to such social situations by the participants (Devos, Strydom, Fouche \& Delport, 2005: 268; Polit \& Beck, 2008: 15-17).

Sampling method: This qualitative survey study used non-probability purposive sampling as the researcher was conducting a study within a small population of 53 employees. This sampling technique is supported by Neuman (2000) who states that this form of techniques is often used when working with very small samples, such as in case study research.

Data collection methods: In-depth interviews were conducted with Regional Centres Customer Care Assistants and supervisors. A qualitative explorative design was used in this study to gather information about their experiences on the current operations and challenges, which are being encountered in their daily operations. This qualitative research method was conducted through semi-structured interviews with a population size of 56. The population of this study was divided into three geographical areas within eThekwini Municipality including central, south and north area. The number of interviews conducted in the north was 26, in the South area 11 and 19 in the North. Furthermore, the Sizakala Care Centres were under the rubric of the Regional Centres unit, which has a three Tier Model, which constitutes First Stop Shops, Thusong Customer Centres and Regional One-Stop Shops. Each and every area has one main Regional One-Stop shops and First Shop, which were distributed, unequally throughout these areas, reporting to the Regional One Stops shops managers. Within eThekwini Municipality, there was one Thusong Customer located in Clermont under the Pinetown Area and 11 First Stop Shop in the Pinetown Area, four in the South and North respectively.

The semi-structured questionnaires were researcher administered to a population size of 56 respondents. The researcher conducted interviews within a period of three months. The following types of questions were consistently posed to the respondents in different locations: the purpose of their current positions, daily routine functions, competencies, challenges and solutions to the identified gaps. This study focussed on the availability of cascading of the IDP to the units and the operational challenges of the structure. To triangulate the in-depth interviews finding, focus groups of 24 Regional Centres Unit employees were conducted. The focus groups, which were later divided into two groups, constituted the customer care supervisors, managers and officers. The groups deliberated on the case study given in the 
input versus output-oriented business in relation to their unit's current status quo. Common findings were later presented, followed by discussions. The researcher acted as the facilitator during these sessions in order to solicit more information as per the in-depth interview findings. The participants were selected because they had certain characteristics in common that relate to the topic being discussed and they were encouraged to discuss and share points of view without any pressure to reach a consensus (Krueger \& Casey, 2000).

Researcher's role and recording of data: In-depth interview were researcher administered to the respondents based on their willingness in participating into the research study, without the breach of their confidentiality. Thus, the researcher documented all deliberations solicited from the interviewees and produced a summary of the key points categorised in terms of the availability and cascading of the unit's strategic plan, working relationship, competencies and challenges on their daily operations, as well as solutions.

Data analysis: This research study adopted a qualitative writing approach at a much lower level of structure based on the researcher's interpretation. The researcher categorised and classified data into meaningful united data to the appropriate category verified relationships and developed conclusions thereof.

\section{Results}

Administrative findings: The research findings conducted within the Regional Centre Unit reveals structural fragmentations, incompetent employees, silo mentality, and the duplication of roles and responsibilities, which hinder the smooth functioning of the customer care centres. The bottlenecks are revealed by the research participants Customer Care Assistants claiming that these were emanating from the non-existence of the unit's strategic plan, where unit structure should have followed the strategic plan rather than emotions. The research findings indicate no evidence of the existence of the approved organogram or structure within the Regional Centre's Unit aligned to the unit's strategic plan, as employees were employed constantly without any approved staff establishment. This is also evidenced by the increased number of employees who were employed through labour brokers and who were later converted to permanent positions. The absence of the Unit's approved strategic plan aligned to the approved Integrated Development Plan (IDP) was supported by the feelings of the Customer Care Assistants and supervisors who claimed that unclear roles and responsibilities contributed to the malfunctioning of the unit.

The research participants have indicated that the Unit's departments were working in silos (in the case of Administration, Sizakala Centres and Amakhosi) which make it impossible for communication across the departments and for the equitable distribution of resources. The study results showed that the silos mentality raised by the respondents has led to poor planning and functions or activities not streamlined which also resulted in the fragmentations of the business processes. The research participants have claimed that such silo mentality has limited information sharing, access and smooth communication amongst the employees. Furthermore, the interviewees indicated that there were politically deployed to this unit without meeting the basic essential requirements of the positions. They also indicated that skills development programmes offered by the municipality were irrelevant. A notable finding of this study was the confirmation of the research participants that they lack basic competencies to perform the primary activities required by the nature of the positions as they were employed against any position in the approved structure. The majority of the participants have also indicated that they have no workload within their sections and there was no return on investments and value for money. The majority of the respondents suggested that they need to be redeployed to other units where they can be utilised effectively.

Focussed groups: Having interviews with officials within the aforesaid unit, groups were then arranged in order success to triangulate the in-depth interview findings. The main rationale for the focussed groups was to elicit information on the underlying factors that have led to the malfunctioning of the Sizakala Centres located in the rural or peri-urban areas. The groups came with common findings, which mostly correlated with the in-depth interview findings. Focussed-group findings indicated that Regional Centres as a whole were disintegrating and working in silos, which perpetuated poor planning, unclear roles and responsibilities, a lack of relevant skills and a top-down management approach. Furthermore, the group results revealed that power within the unit was centralised, which was characterised by the extravagance 
of money; marginalising of the line managers during the recruitment and selection processes and grade anomalies (such as in the case of Manager: Amakhosi was at Grade 12 and Manager: Operations at 15 with a similar work load) were also confirmed by the focussed-group findings. The participants indicated that skills development programmes offered to employees in the previous and current years were not responsive to the needs of the Regional Centre's Unit. Poor communication within the Unit has led the delegation processes to fail as line managers fail to communicate with their subordinates, which was also aggravated by seldom-held meetings.

Discussion: The primary objectives of this study are to determine the availability of the strategic plan and how it is cascaded from the IDP. Furthermore, the main objective of this study was to investigate the underlying and root causes of the malfunctioning of the customer care centres located in peri-urban and rural areas. This finding of the absence of the strategic plan aligned to the IDP within the Regional Centre's unit is inconsistent with the research findings of Mbele (2010: 54); Ridder, Brus \& Spier (2006: 87) and Crous (2005: 3 ) revealing the processes that supports strategy and organisational strategy is supporting customer needs. The research findings on the absence of the strategic plan aligned to the approved IDP is also in disagreement with Fourie \& Jager (2005) who suggest that line employees should be oriented on the strategic plans including mission, goals (Strydom, 2004: 15), strategies and business processes of the organisation. The study result indicate on the silos working relationships within the Unit and is supported by Engele (n.d.) who cited the results of silo on operation and Brand \& Klein (2012: 23) who have mentioned that municipalities have been historically and continue to be silo-ed organisational structures. The finding on the hampering of the speedy service delivery is in agreement with Kotler \& Andreasen's (1996: 3799-380) findings focussing on the unresponsive actions of the front line employees in municipalities.

The research findings on the deficiencies in competencies in Regional Centre Unit's employees is in accordance with the study conducted by Rapea (2004: 33-34) \& Marais \&Kroukamp (2005: 121) citing that the competencies needed for leading customer care were not conspicuous in the latter unit's employees. The scarcity of essential skills to be possessed by the Customer Care Assistants to be able to execute customer-oriented functions and to be responsive to customer needs (Fouries \& Jager, 2005) is in agreement with the study conducted by Furguson \& Milliman (2001: 56).The finding of poor communication commonly encountered during focus groups within the Unit supports the findings of Engele (n.d) who claimed that poor internal communication has the tendency to exacerbate silo mentality in organisations. The research findings of this study have revealed grade anomalies within similar positions with the same work load as is not in agreement with any study conducted in the public sector, which compromises the findings of this study. Furthermore, there was not a study conducted in the reviewed literature that was linked to management approaches or models, redeployment of employees to other units and the convening of meetings in local government.

\section{Conclusion and Recommendations}

The study has revealed underlying operational bottlenecks, which directly hamper quality customer care service and delivery within eThekwini Municipality's Regional Centres Unit. The non-existence of the approved unit's strategic plan aligned to the IDP has been seen as the main cause of structural challenges, which directly paralyses the smooth operation of the Regional Centre's Unit. The most notable finding of this study is the resultant of the fragmentation of the structure, which has exacerbated silos working relationships, unclear roles and responsibilities, and incompetency. Therefore, it is envisaged that the Regional Centres Unit should craft and adopt a strategic plan aligned to the IDP. It is also advisable for the unit to involve all key stakeholders and unit employees during the strategic planning sessions for buy-in and ownership by all employees. Upon approval of the strategic plan, a new structure or organogram needs to be crafted that is aligned to the strategic plan. Lastly, crafting of the job descriptions aligned to the strategic objectives should be devised followed by an accurate evaluation of positions using modern scientific softwares. In order for the unit to change with less resistance to change, a management model or leadership style should be clearly articulated to be aligned with the transition, accompanied by regularly monitored meetings with clear outputs.

The study has some limitations when applying the findings of this study. The unavailability of the approved organogram and job descriptions to determine the number of employees in the staff establishment lessen the true reflection of the unit at large. Employee failure to furnish the researcher with proof of qualifications was a limitation as it was difficult to genuinely verify the existence of the qualifications. Notwithstanding the limitations of the study, a Business Process Re-engineering (BPR), 
Business Process Management (BPM) and Work-Study exercise need to be conducted with the aim of mapping the AS-IS and TO-BE business processes and calculate the workload for the existing employees. Future research could look at the private sector customer service models and how these can be applied in the public sector realm, with the aim to improve efficiency and effectiveness.

\section{References}

Baily, G. (1996). Customer Care: Making It Work. Managing Service Quality, 6(3), 28-40.

Brand, K. \& Klein, R. (2012).Embedding Urban Sustainability Considerations into IDPs and SDBIs. IMFO, 20-26.

Crous, M. (2005).Leading Internal Customer Care for External Excellence. Journal of Public Administration Conference Proceedings. October 2005.

De Vos, A. S., Strydom, H., Fouché, C. B. \& Delport, C. S. L. (2005). Research at grass roots for the social sciences and human service professions.2nd Ed. Pretoria: VanSchaik Publishers.

Firer, S. (2002). Strategic Planning, Can it add value to a business? People Dynamics. Journal of the South African Institute of People Management, 20(5), 17-21.

Fourie, W. L. D. \& Jager, J. D. (2005). Increasing Customer Satisfaction through enhancing service delivery: An Internal Marketing Approach. Journal of Public Administration, 40(3.1), 229-246.

Haycock, E. \& Labuschagne, H. J. (2006). Achieving performance excellence by aligning strategies and operations in local government context in South Africa. Politeia, 25(3), 257-272.

Kaplan, R. S. \& Norton, D. P. (2004). Strategy Maps Converting Intangible Assets into Tangible Outcomes. Boston, MA: Harvard Business School Press.

Katoma, F. N. \& Ungerer, M. (2011). The role of middle managers in strategy execution: a case study of a Local Authority Council in Namibia. Politeia, 30(3), 31-53.

Kotler, P. \& Andreasen, A. R. (1996). Strategic Marketing for Non-profit Organisations. Third Edition, Englewood Cliffs: Prentice Hall.

Krueger, R. A. \& Casey, M. A. (2000). Focus Groups: A Practical Guide for Applied Research (3rdedn), Thousand Oakes: CA, SAGE.

Marais, L. \& Kroukamp, H. J. (2005). Managerial Skills and Institutional Capacity for Municipal Service Delivery. Journal of Public Administration, 40(20), 121-135.

Mbele, N. (2010). Turnaround Strategy: Implications for Municipalities. Management Toda, 52-54.

Miller, A. \& Dess, G. G. (1996). Strategic Management. 2nd ed. New York: McGraw-

Mintzberg, H. (1994). The rise and fall of strategic planning. New York: The Free Press.

Neuman, W. L. (2000). Social research methods: Qualitative and quantitative approaches ( $4^{\text {th }}$ ed). Boston: Alyn and Bacon.

Odendaal, M. (2003). Sustainable local communities: What is the role of South African Metropolitan Governments? Journal of Public Administration, 38(1), 43-58.

Pryor, M. G. D., Anderson, L. A., Toombs, A. \& Humphreys, J. H. (2007).Strategic implementation as a core competency. Journal of Management Research, 7(1), 3-14.

Rapea, A. P. (2004). Deepening Professionalism in the Public Service. Service Delivery Review, 3(3), 30-42.

Republic of South Africa. Local Government: Municipal Structures Act 117 of 1997, Government Gazette. No. 19614.

Republic of South Africa. Local Government: Municipal Systems Amendment Act 7 of 2011, Government Gazette. No. 34433.

Republic of South Africa. White Paper on transforming public service delivery (Batho Pele White Paper. (Notice No. 1459 of 1997. Gazette No. 18340, Vol. 388. 1 October) Pretoria: Government Printers.

Ridder, H. G., Bruns, H. J. \& Spier, F. (2006). Managing implementation processes. The role of public managers in the implementation of accrual accounting: evidence from six case studies in Germany. Public Management Review, 8(1), 87-118.

Robbins, S. P., Odendaal, A. \& Roodt, G. (2003). Organisational Behaviour: Global and Southern African Perspectives. Cape Town: Pearson Education South Africa.

Strydom, J. (2004). Introduction to Marketing. Cape Town: Juta and Co Ltd.

Swanson, R. A. \& Holton, E. F. (1997). Human Development: Research Handbook: Linking Research and Practice, San Francisco: CA. Berret-Koehler Publishers.

Van Rooyen, E. (2001). Integrated development and the Brownfields phenomena. Journal of Public Administration, 36(1), 61-79.

Vatala, S. W. (2005). Synergies between an Integrated: A Service Delivery and Budget Implementation Plan (SDBIP) and other Related Plans for 2005-2006 Financial year. Journal of Public Administration. Conference proceedings. 